\title{
PHYSICS NOTES
}

Number 1 


\title{
PHYSICS NOTES
}

\section{EDITED BY}

Philip W. Anderson, Arthur S. Wightman, and Sam B. Treiman

\author{
1. RENORMALIZATION GROUP \\ by Giuseppe Benfatto and Giovanni Gallavotti
}

(1995) 


\section{RENORMALIZATION GROUP}

\section{Giuseppe Benfatto and Giovanni Gallavotti}

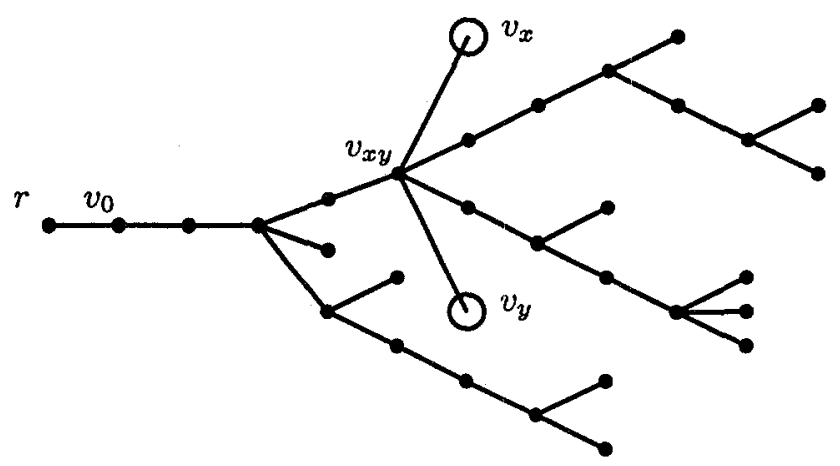

Physics Notes

Princeton University Press

Princeton, New Jersey 


\section{Copyright 101995 by Princeton University Press}

Published by Princeton University Press, 41 William Street,

Princeton, New Jersey 08540

In the United Kingdom: Princeton University Press, Chichester, West Sussex

\section{All Rights Reserved}

\section{Library of Congress Cataloging-in-Publication Data}

\section{Benfatto, Giuseppe, 1944-}

Renormalization group / Giuseppe Benfatto and Giovanni Gallavotti.

p. cm. - (Princeton physics notes)

Includes bibliographical references and indexes.

ISBN 0-691-04447-3 (alk. paper). - ISBN 0-691-04446-5 (pbk. : alk. paper)

1. Renormalization group. 2. Critical phenomena (Physics)

I. Gallavotti, Giovanni. II. Title. III. Series.

$$
\text { QC20.7.R43B46 } 1995
$$

530.1 '33-dc20 95-10533

The publisher would like to acknowledge the authors of this volume for providing the camera-ready copy from which this book was printed

Princeton University Press books are printed on acid-free paper and meet the guidelines for permanence and durability of the Committee on Production Guidelines for Book Longevity

of the Council on Library Resources

Printed in the United States of America

by Princeton Academic Press

109876654321

10987654321 (Pbk.) 